\title{
Proceedings
}

\section{Research on Challenges and Prospects of Digital Agriculture ${ }^{t}$}

\author{
Mihai Anitei ${ }^{1}$, Cristina Veres ${ }^{2, *}$ and Adrian Pisla ${ }^{3}$ \\ 1 Department of Management and Economic Engineering, Faculty of Machine Building, Technical University \\ of Cluj-Napoca, 400114 Cluj-Napoca, Romania; mihai.anitei@yahoo.com \\ 2 Department of Industrial Engineering and Management, Faculty of Engineering and Information \\ Technology, George Emil Palade University of Medicine, Pharmacy, Science and Technology of Târgu-Mures, \\ 540139 Târgu-Mureș, Romania \\ 3 Department of Design Engineering \& Robotics, Faculty of Machine Building, Technical University of \\ Cluj-Napoca, 400114 Cluj-Napoca, Romania; adrian.pisla@muri.utcluj.ro \\ * Correspondence: cristina.veres@umfst.ro \\ + Presented at the 14th International Conference on Interdisciplinarity in Engineering-INTER-ENG 2020, \\ Târgu Mureș, Romania, 8-9 October 2020.
}

Published: 28 January 2021

\begin{abstract}
The actual pandemic context highlighted once again the huge importance of agriculture in the society and create a path to a speeded-up digitalization. As soon as the virus crisis will end, countries will start reprioritizing their values and do investments accordingly; agriculture will regain focus. In order to get an overview image on the challenges and farmers needs in agriculture in the context of digitalization, a questionnaire-based research was made, collecting data from Romanian experienced farmers and business experts in agriculture.
\end{abstract}

Keywords: digital agriculture; farming; digitalization; farmers' challenges; EU green deal

\section{Introduction}

Agriculture plays an important role in providing food security and sustainability for the people in any country [1]. In the same time, nowadays agriculture faces several important challenges and limitations. In the latest decades, innovation significantly contributed to facilitate the fieldwork and to increase productivity.

As digitalization is impacting each component of our lives, different forms of digitalization started to be introduced in agriculture like: sensors, IoT (internet of things), big data, 3D printing, artificial intelligence, digital twins, augmented reality, system integration and the list may go on.

The aim of the research work is to identify the challenges and the prospects of agriculture in the context of digitalization, in the experts' and farmers' view. The data was collected form 19 experienced farmers and business experts in Romania within the month of August 2020. Of our best knowledge, this is the first research on Digital Agriculture, organized in Romania after pandemic Covid-19 expansion, whose effects can be considered key drivers to a future accelerated digitalization.

This research starts with a presentation of the actual global challenges that agriculture faces and a brief description of the Romania's agricultural profile. Then there are presented the questionnaire details and findings. 


\section{Digital Agriculture: Challenges and Prospects}

\subsection{Global Agriculture Challenges}

Speaking about agriculture, we can't ignore the influence and impact of current global trends which are shaping the world development, as well as their inter-dependence: population growth, urbanization process, population aging, climate change, economies' digitalization, advancement of globalization and liberalization processes. These trends may contribute in changing the pattern of agriculture and agri-food system and stimulating innovation capacity in the coming years [2].

One of the main challenges of tomorrow's agriculture is the growth of the population.

According to World Population Prospects, United Nations' projected in 2019 that the world's population would grow from 7.7 billion in 2019 to 8.5 billion in 2030, 9.7 billion in 2050 and 10.9 billion in 2100 [3].

How will be ensured the satisfaction of a vital physiological need of such rapid growth, providing food security for another two billion people in the next 30 years?

Because of the rural poverty, the lack of jobs and poor infrastructure the share of the urban population has grown steadily in recent decades. Together with the population aging, this will have an influence on food consumption behavior and may lead to issues related to logistics, which will need a rigorous planning.

Worldwide there is a movement towards more sustainable systems.

By now, the use of irrigation, fertilizers and expansion of agricultural land has made possible to face the rapid growth of population. Nevertheless, we should take into account the intensification of soil use, the deforestation, the land degradation, the water pollution, land losses by erosion, desertification, salinization, the rise of the sea level and other issues, which cumulated rise up new challenges to the long-term agricultural productivity.

The process of globalization, the free movement of goods, capital concentration, services availability, technology and information, influences the dynamic of agriculture. Increased investments in agriculture, the development of the food industry and the growth of the international trade of food are all effects of globalization and liberalization. The current pandemic caused a slowdown in the globalization process and people focused their attention to the local markets, at least for a determined period of time.

Digitalization, the socio-technical process of applying digital innovations, is an increasingly ubiquitous trend. Digitalization comprises phenomena and technologies such as big data, internet of things (IoT), augmented reality, robotics, sensors, 3D printing, system integration, ubiquitous connectivity, artificial intelligence, machine learning, digital twins and blockchain among others [4-7]. Digital technologies and new data analysis using artificial intelligence will influence each stage of the agri-food chain: primary production, processing, distribution, consumption.

Today, drones allow seeds planting in areas where tractors and people do not have access, thus erasing without trace specific limits in agriculture. New technologies can plant, irrigate soil according to its parameters, obtain real-time information about the state of crops, identify weeds and diseases, do pesticides application and precision harvesting, analyze data and take action.

\subsection{Digital Agriculture in Romania}

According to an analysis performed by professional services firm PwC, Romania is one of the European countries with the highest potential in agriculture, with the sixth biggest used agricultural area in EU, but with a low productivity due to several factors [8].

The country presents a huge development potential for Digital Agriculture, based on a series of facts and advantages.

Romania poses an important agricultural profile, rich soil, good environmental conditions, old tradition of working the land, ultra-high speed of internet (Romania has the 5th fastest internet in world, according to World Population Review, 2020 [9]), existence of highly appreciated IT specialists and software developers are all strong arguments to sustain its' agricultural digitalization potential. 
On the other hand, the predominantly small-farm structure of the country, fragmented land ownership and low levels of mechanization are palpable barriers to rapid system shift [10].

Globally, digitalization and Industry 4.0 will contribute to speed up innovations in agricultural field. It's a matter of time to reach up a new level of agricultural development in Romania.

\subsection{Challenges and Prospects of Digital Agriculture in Farmers' View}

In analyzing the challenges, it is important and interesting to notice how agriculture is seen in farmers' eyes in the context of digitalization, what limits and challenges do they face and what opportunities and future development they foreseen. To find out, a questionnaire survey, as one of the qualitative methods, was created and distributed. The questionnaire was sent online to targeted Romanian farmers and the collected data was analyzed.

Within the elaborated investigation to the questionnaire session participated 19 respondents from several counties of Romania, of which 17 farmers of small, medium and big farms and 2 business experts. The envisaged regions are: Călărași (CL), Olt (OT), Dolj (DJ), Suceava (SV), Iași (IS), Ialomița (IL), Tulcea (TL), Mureș (MS) and Ilfov (IF) (see Figure 1).

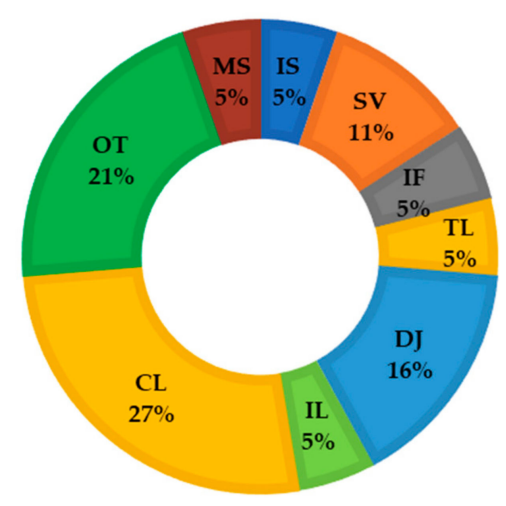

Figure 1. Distribution of respondents by county.

The questionnaire was formed of 4 identification questions and 9 open questions related to the digital agriculture.

From the survey $100 \%$ of the participants agreed that digitalization is an opportunity for their activity; none of them consider digitalization a threat. Digitalization in farmer's view is a real help, which will lead to maximum efficiency in the carried-out activity.

Participants were asked the express terms associated to Digital Agriculture. Most of them mentioned "indispensable" (26.3\%), "efficiency" (26.3\%) and "necessity" (21.1\%), but also "future", "help for farmers", "evolution", "yield", "profitability", "development" and "maximum potential".

When they were asked about how they see digital agriculture today and in future all the participants gave a good feedback, and hereby are some relevant answers:

- Digital agriculture today is a delicate subject for Romanian farmers due to the costs. Only large farms can afford these costs. Today, everyone knows the benefits of digital systems, but very few have been able to financially support these investments.

In the future, I believe that digitalization must not be missing from any farm in order to be profitable;

- Today, it helps increase farm yield, helps the farmer decide when and how much to apply. In the future, we hope that digital agriculture can be put into practice on a larger scale;

- Digital agriculture is the tool that helps reaching the maximum of the production potential in conditions of economic efficiency; 
- Digital agriculture will completely change the relationship between the farmer and the other players in near future.

When speaking about challenges and limits they face, $41.2 \%$ of the respondents claimed the lack of qualified staff, $31.6 \%$ mentioned the lack of financial funds, and $21.1 \%$-the digitalization costs. Figure 2 presents the Pareto chart of the mentioned challenges, distributed in descending order of their percentage.

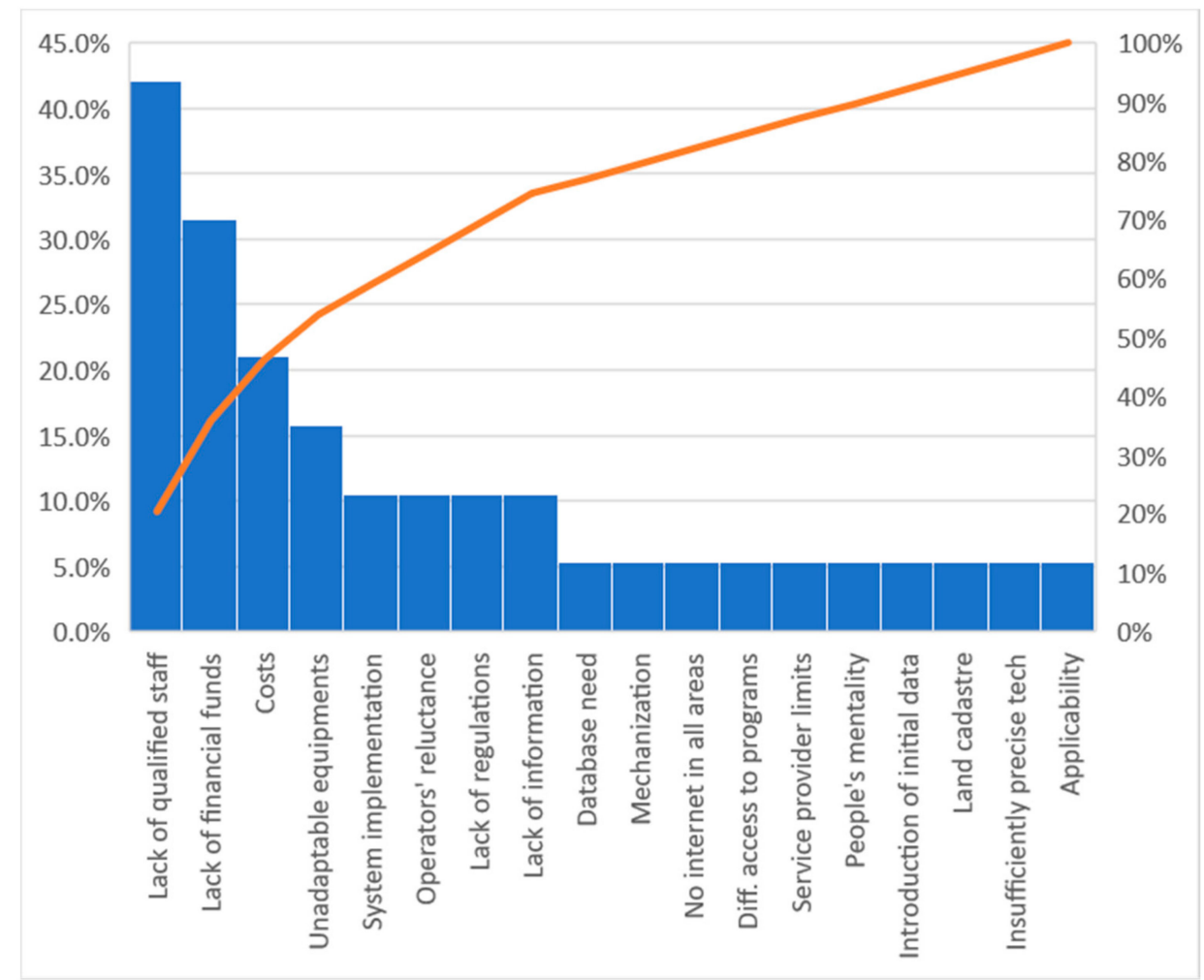

Figure 2. Challenges met by respondents.

An analysis on challenges and limits of digital agriculture wouldn't be complete without finding out what would help farmers to overcome the identified obstacles.

Here is what was found to be useful to speed up the digitalization in their activities:

- More information in this regard;

- Specialization courses and trainings in its use;

- Demo periods would be helpful;

- Friendlier interfaces;

- Easier access to digital farming programs;

- Targeted funds;

- Government investments;

- High quality services;

- Lower costs;

Expanding the number of respondents to the questionnaire would bring more value to the research and contribute to an improved overview.

\section{Research and Methods}

The bibliographical study method was used to study recent specialty literature, deepen knowledge and gain a good understanding of the field. 
The questionnaire survey, as one of the qualitative methods, was used in the research. The questionnaire was sent to targeted people and the obtained data was analyzed.

The purpose of this research was to get an overview image of the challenges and prospects of digital agriculture, by collecting and analyzing data obtained from Romanian farmers and agricultural experts. The aim of the research is to progress in the direction of the EU Green Deal that will mobilize the research and innovation potential to foster sustainable societal transition and to create a Project with visible results from research and innovation activities that can provide clear solutions for a better governance of the green and digital transition, social and value chain innovation. The actual research and the future Project, being anchored in the present pandemic situation, must help to the green and digital recovery, increasing societal resilience in agriculture.

Within the Green Deal, to agriculture is addressed a special call, the call no 6 "Farm to Fork: testing and demonstrating high impact innovations to address food system challenges in a place-based context.", which aims to transform European food systems into a global standard for sustainability and find solutions to actual challenges.

The envisaged Project will be targeting the value chain components impact for the fertilizers' and harmful nutrients' reduction towards zero pollution by applying digital solutions within a demonstration pilot scenario, focused on three aspects:

- $\quad$ Align the three sustainability's dimensions:

$$
\begin{array}{ll}
\bigcirc & \text { economic; } \\
& \text { climate/environment; } \\
\text { social/health. }
\end{array}
$$

- Maximize synergies;

- Address to a specific challenge: to develop an appropriate mix of innovations.

As final scope can be considered the pilot demonstrating solution at TRL5 level (Technology Reediness Level) focused on systemic innovations that increase resilience of food systems to shock and stresses, considering:

- Reducing the GHG (Green House Gas) emissions and carbon blocking and/or storage;

- Reducing energy use and increasing energy efficiency in processing;

- Reducing the use and increasing the efficiency of fertilizers;

- Moving towards zero pollution by reducing the losses of nutrients from fertilizers;

- Reducing losses and waste, while avoiding unsustainable packaging [11];

- The potential to scale up the solution to national level by 2025 and EU level by 2030, including the presentation of obstacles and the stakeholder's motivation;

- Identify, explain and quantify, the used KPI (Key Performance Indicators), about how the solution will deliver the expected impact.

\section{Conclusions}

Agriculture, as one of the main pillars of society's sustainability, has been shaped by digital era.

Big data, internet of things (IoT), augmented reality, robotics, sensors, 3D printing and other high technology is changing the way we are feeding a growing world population.

After conducting a research among Romanian farmers on digital agriculture we discovered the limits and challenges they face, as well as their needs to speed up digitalization. The lack of qualified staff represents the biggest concern and challenge for farmers, as digital equipment and machines requires specific skills and competences. The second most important challenge is related to the lack of financial funds. High technology machines are expensive and difficult to maintain. The lack of funds affects especially small and medium-size farms, which should be extremely profitable to be able to afford expensive systems. 
As a solution to these two and other challenges, government investments, specialized training, lower costs, an easier access to digital farming programs, a friendlier interface etc. are considered by farmers helpful to speed up digitalization of their activity.

In conclusion, farmers are aware of the benefits of digital agriculture and do want to digitalize their activities, but some challenges seem to limit them. As the technologization of farms is costly and many farms can't afford such revamping projects, perhaps in addition to the effort of farmers some future supported by authorities' programs could accelerate digitalization.

As a practical pilot demonstrator, the research group is envisaged to provide a Project proposal within the EU Green Deal Pact.

Author Contributions: M.A. defined the basic idea and direction of the research, contributed to developing the questionnaire and collecting data, C.V. facilitated the writing of the research, did the analysis of data and enriched the article with relevant bibliographical references and A.P. guided the research, approved the methodology and added valuable input on EU Green Deal Pact. All authors have read and agreed to the published version of the manuscript.

Funding: This research received no external funding.

Conflicts of Interest: The authors declare no conflict of interest.

\section{References}

1. Anshari, M.; Almunawar, M.N.; Masri, M.; Hamdan, M. Digital Marketplace and FinTech to Support Agriculture Sustainability. Energy Proc. 2019, 156, 234-238. [CrossRef]

2. Fîntîneru, G. Tendințe și Perspective Globale în Agricultură. In Agricultura. Concepte și Instrumente Operationale. Caiet Documentar 4; Stoian, M., Aniței, M., Eds.; Editura Club București: București, România, 2019; pp. 35-46.

3. United Nation. Population Facts. December 2019. Volume 6. Available online: https://www.un.org/en/ development/desa/population/publications/pdf/popfacts/PopFacts_2019-6.pdf (accessed on 3 August 2020).

4. Klerkx, L.; Jakku, E.; Labarthe, P. A review of social science on digital agriculture, smart farming and agriculture 4.0: New contributions and a future research agenda. NJAS-Wagening J. Life Sci. 2019, 90-91, 100315. [CrossRef]

5. Alm, E.; Colliander, N.; Lind, F.; Stohne, V.; Sundström, O.; Wilms, M.; Smits, M. Digitizing the Netherlands: How the Netherlands Can Drive and Benefit from an Accelerated Digitized Economy in Europe; Boston Consulting Group: Stockholm, Sweden, 2016.

6. Smith, M.J. Getting value from artificial intelligence in agriculture. Anim. Prod. Sci. 2018, 60, 46-54. [CrossRef]

7. Tilson, D.; Lyytinen, K.; Sørensen, C. Research commentary-digital infrastructures: The missing IS research agenda. Inf. Syst. Res. 2010, 21, 748-759. [CrossRef]

8. Business Review. Available online: https://business-review.eu/news/romania-has-significant-potential-inagriculture-but-low-productivity-says-pwc-romania-study-132113 (accessed on 1 August 2020).

9. World Population Review. Available online: https://worldpopulationreview.com/country-rankings/internetspeeds-by-country (accessed on 3 August 2020).

10. Highclere Consulting. Available online: https://highclere-consulting.com/en/digitalization-in-romanianagriculture-three-solutions-to-bridge-two-eu-2030-agendas/ (accessed on 5 August 2020).

11. Tiko Pro. Available online: https://www.tiko-pro.eu/success-stories-details/green-deal-call-area-6-farm-tofork (accessed on 5 August 2020).

Publisher's Note: MDPI stays neutral with regard to jurisdictional claims in published maps and institutional affiliations.

(C) 2021 by the authors. Licensee MDPI, Basel, Switzerland. This article is an open access article distributed under the terms and conditions of the Creative Commons Attribution (CC BY) license (http://creativecommons.org/licenses/by/4.0/). 